Document downloaded from:

http://hdl.handle.net/10251/102614

This paper must be cited as:

Presenda-Barrera, A.; Salvador Moya, MD.; Vleugels, J.; Moreno, R.; Borrell Tomás, MA. (2017). Fretting fatigue wear behavior of $Y$-TZP dental ceramics processed by nonconventional microwave sintering. Journal of the American Ceramic Society. 100(5):18421852. doi:10.1111/jace.14769

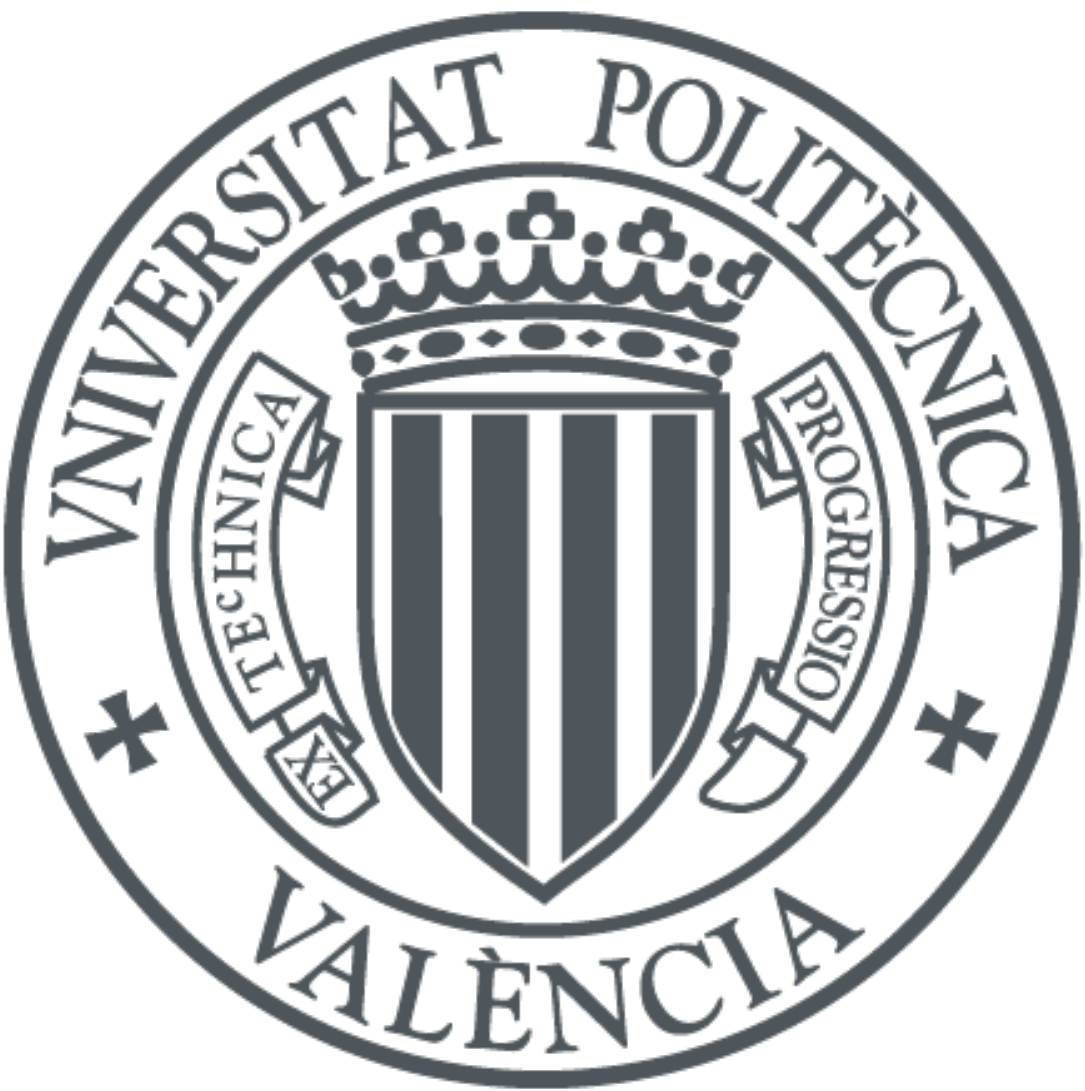

The final publication is available at

http://doi.org/10.1111/jace.14769

Copyright Blackwell Publishing

Additional Information 


\title{
Fretting fatigue wear behavior of Y-TZP dental ceramics processed by non-conventional microwave sintering
}

\author{
Álvaro Presenda ${ }^{1}$, M. Dolores Salvador ${ }^{1}$, Jozef Vleugels $^{2}$, Rodrigo Moreno ${ }^{3}$, Amparo Borrell ${ }^{1}$ \\ ${ }^{1}$ Instituto de Tecnología de Materiales (ITM), Universitat Politècnica de València, Camino de \\ Vera s/n, 46022, Valencia, Spain \\ ${ }^{2}$ KU Leuven, Department of Materials Engineering (MTM), Kasteelpark Arenberg 44, B-3001 \\ Leuven, Belgium \\ ${ }^{3}$ Instituto de Cerámica y Vidrio (ICV), Consejo Superior de Investigaciones Científicas (CSIC), \\ E-28049 Madrid, Spain \\ *Corresponding author at: Instituto de Tecnología de Materiales (ITM), Universidad Politécnica \\ de Valencia, Camino de Vera s/n, 46022, Valencia, Spain. Tel.: + 34633868959. \\ E-mail address: alpreba2@upv.es (A. Presenda)
}




\begin{abstract}
The fretting wear behavior of self-mated Y-TZP dental materials obtained by non-conventional microwave and conventional sintering has been investigated. Two 3Y-TZP materials, a widely utilized commercial dental ceramic (LAVA) and a lab-prepared 3Y-TZP powder based equivalent have been assessed. Relative density and mechanical properties as well as the grain size variations upon sintering have been evaluated. After exposure to selected gross slip regime fretting wear conditions, the wear tracks have been characterized allowing the measurement of the coefficient of friction, track profiles, and pit features. The results indicate that microwave sintering results in a similar fretting wear behavior as observed for conventional sintered 3Y-TZP, since the measured volumetric wear loss is of a comparable order of magnitude. Regarding the influence of the grain size, the analysis revealed that a large grain size $(>300 \mathrm{~nm})$ results in an increased wear volume and that a higher resistance to fretting wear is constrained to a mid-range particle size. Since the fracture toughness of all investigated ceramic grades was comparable, the influence of the fracture toughness could not be assessed. Abrasive grooving, delamination and microcracking have been identified as major wear mechanisms inside the wear tracks for both conventional and microwave sintered 3Y-TZP. In general, microwave sintering can provide 3YTZP dental materials with a comparable fretting wear resistance as that observed for conventional sintering using lower dwell sintering temperatures and a shorter processing time.
\end{abstract}




\section{Introduction}

The wear resistance of biomaterials aiming to replace structural elements in the human body is critical for an optimum long-term durability. Particularly, a study of the tribological behavior is very important for orthopedic and orthodontic uses, as interactions between surfaces and friction are quite common. The performance under wear conditions of yttria-stabilized zirconia polycrystalline (Y-TZP) ceramics make these materials an interesting alternative as structural bioceramics. Even though orthopedic applications of all-zirconia materials have been almost completely abandoned after the catastrophic failures in the early 2000's ${ }^{1}$, restorative dentistry has adopted zirconia-based ceramics for applications as prostheses and implants due to their biocompatibility, physical, aesthetic and mechanical properties ${ }^{2,3}$. Since teeth are subjected to contact and friction between surfaces due to grinding during the mastication process and, in some cases, due to mouth disorders such as bruxism, there is a need to investigate the wear resistance of Y-TZP materials that are required to act as replacements of teeth.

Fretting wear is characterized by a constant reciprocating sliding motion between two bodies at a low amplitude, usually no more than a few hundred micrometers ${ }^{4,5}$. Due to the small displacements involved, removed material can be trapped between contacting surfaces influencing the wear damage caused ${ }^{5}$. During the fretting process, three wear regimes arise as wear progresses: stick, partial slip and gross slip ${ }^{6,7}$. Moreover, surface damage is produced over most of the contact where slip occurs. Several configurations based on displacement modes can be used to describe fretting wear, being linear, radial and circumferential, three of the most commonly encountered in engineering applications. The radial and linear mode can be applied to describe wear of dental systems due to the nature of the contact. The linear mode corresponds to a tangential displacement resulting in high friction and tangential forces between the interacting surfaces, while the radial mode is concerned with exerting a normal force as the contact between surfaces is perpendicular. The linear mode can result in a higher rate of material removal due to the high friction force that results from tangential sliding and is representative of the grinding 
processes teeth are subjected to. Hence, the focus of this study is based on the linear mode in a ball-on-flat setup.

Microwave sintering is alternative material processing technique that differs significantly from conventional sintering due to the nature of the heat generation and transfer and densification mechanisms involved. This method presents itself as a fast, economical and flexible processing tool. Some of the most important advantages over conventional sintering include a volumetric direct heating, lower energy consumption and production costs, reduction of processing time, higher heating rates, and in some cases even an improvement in the physical properties of the consolidated material ${ }^{8,9}$. As a consequence, scientific interest in this novel technique has been developed progressively. In a general sense, microwave sintering increases the densification of the material at lower dwell temperatures when compared to conventional sintering ${ }^{10,11}$, employing shorter times and less energy 12, 13, and resulting in an improvement of the microstructure and mechanical properties in some cases ${ }^{14,15}$.

Since microwave sintering allows for a modified microstructure, especially by significantly reducing the grain size, due to the heating mechanisms involved, the wear behavior of Y-TZP ceramics is affected. In general, the literature suggests that microwave sintering of zirconia can result in comparable mechanical properties and high degrees of densification at lower dwell temperatures and significantly shorter sintering times than for conventional sintering ${ }^{16-19}$. Moreover, some studies have demonstrated that microwave sintered materials exhibit enhanced crystallinity ${ }^{20}$ and improved mechanical properties ${ }^{15,21,22}$. Additionally, some authors have suggested that smaller grain sizes can enhance the wear resistance of ceramics ${ }^{23-25}$.

The purpose of this work is to evaluate the tribological behavior under dry fretting fatigue conditions of microwave sintered Y-TZP materials by a direct comparison with conventional sintered 3Y-TZP dental ceramics and study differences in terms of wear behavior that may arise as a consequence of microwave heating. Mechanical properties, such as hardness and fracture toughness, have been determined and their influence on the wear rate has been elucidated. 
Tribological parameters such as coefficient of friction (COF) and wear volume loss are investigated along with a qualitative analysis of the wear pits.

\section{Materials and Methods}

\section{$2.1 \quad Y$-TZP materials}

The starting materials considered in this study are a commercial dental Y-TZP material (LAVA Zirconia, 3M ESPE, St. Paul, MN, USA) and a lab-optimized commercial 3Y-TZP powder based ceramic (TZ-3YSE, Tosoh, Tokyo, Japan). The former has been provided as a pre-sintered block with a green density of $65 \%$, and then cut and shaped into the corresponding dimensions: cylindrical bodies with a diameter of $10 \mathrm{~mm}$ and a height of $4 \mathrm{~mm}$. The latter consists of a TZ3YSE ceramic powder that has been dispersed by colloidal processing in water with the aim of optimizing the rheological behavior of the suspension in order to obtain a more homogeneous powder in terms of particle size. Specific details on the preparation of the dispersing conditions are provided in the works of Rayón et al. ${ }^{26}$ The ceramic powder is finally obtained by freezedrying after homogeneous dispersion. The powder has been compacted with the aid of a punch and a die of the corresponding dimensions to a pressure of $200 \mathrm{MPa}$ to form green bodies with a diameter of $10 \mathrm{~mm}$ and a height of $4 \mathrm{~mm}$ and a green density of approximately $60 \%$. Important physical properties and characteristics of both starting materials are summarized in Table 1. Small amounts of alumina are present in both materials to enhance sintering kinetics ${ }^{27}$.

\subsection{Sintering conditions}

Both zirconia materials have been processed by conventional and microwave sintering. For conventional sintering, a Thermolyne type 46100 (Thermo Fisher Scientific, Madrid, Spain) was used with a heating/cooling rate of $10{ }^{\circ} \mathrm{C} / \mathrm{min}$ at $1400{ }^{\circ} \mathrm{C}$ for $2 \mathrm{~h}$ in air. The total processing time was $380 \mathrm{~min}$. Microwave sintering has been performed in air applying a heating/cooling rate of $100{ }^{\circ} \mathrm{C} / \mathrm{min}$ and a dwell temperature of $1200{ }^{\circ} \mathrm{C}$ for $10 \mathrm{~min}$. Total processing time was $30 \mathrm{~min}$. An experimental microwave system with a rectangular cavity was used. The selected processing 
parameters are based on previous studies where sintering conditions have been optimized to obtain highly densified materials with comparable physical and mechanical properties for both conventional and microwave sintering. ${ }^{15,17,28}$ The sample temperature during microwave sintering was monitored with a two-color pyrometer (Optris CT-Laser LT, Berlin, Germany), directly focused on the sample surface through an aperture in the upper wall of the cavity. The emissivity of the Y-TZP grades has been previously calculated for calibration of the pyrometer. Real-time temperature monitoring is carried out by a feedback loop system software that adjusts the dimensions of the cavity to control microwave absorption and, hence, temperature. For convenience, the nomenclature of the commercial LAVA and the lab-optimized Y-TZP ceramic powder are referred to as $\mathrm{LV}$ and $\mathrm{LAB}$, respectively, and the suffix CS and MW refer to conventional or microwave sintering, respectively. Four tests have been conducted for each sintering condition and material.

\subsection{Fretting test setup}

Fretting tests have been carried out with a ball-on-plate configuration, as shown in Figure 1. YTZP balls (TZ-3Y, Tosoh, Japan) with a diameter of $10 \mathrm{~mm}$ are used as counter material in all tests. The system consists of a computer-controlled tribometer where the sample to be evaluated is mounted on a translation table, which oscillates at a pre-defined frequency. The ball is fixed so that only tangential fretting wear occurs. Specimens are fixed to the sample holder that allows movement in the $x$ and $y$ directions. The experimental fretting parameters were kept constant for comparative reasons as follows: normal load $=8 \mathrm{~N}$, frequency $=5 \mathrm{~Hz}$, number of cycles $=100,000$ and $x$ direction displacement $=200 \mu \mathrm{m}$. Fretting conditions have been selected based on preliminary studies indicating that these conditions allow generating wear tracks of considerable size and depth within reasonable testing times. Additionally, these parameters are expected to yield a gross slip fretting behavior. Previous to the fretting wear tests, Y-TZP specimens have been mirror-polished with colloidal diamond suspension down to $0.25 \mu \mathrm{m}$. The fretting test equipment is a home-made tribometer designed and built at the Department of Materials Engineering at KU Leuven. According to Zheng et al. ${ }^{29}$, friction and wear tests of dental 
components should be carried out ideally in a reciprocating sliding mode to better simulate the mastication behavior. All tests have been carried out at room temperature and under ambient relative humidity conditions. At least two fretting tests have been carried out for each specimen.

\subsection{Materials and wear track characterization}

The density of the sintered ceramics has been determined with the Archimedes method following the ASTM-C-373 Standard. For relative density calculations, a theoretical density of $6.05 \mathrm{~g} / \mathrm{cm}^{3}$ was used. Hardness, $H$ and indentation fracture toughness, $K_{I C}$, have been determined with a Vickers indenter (FV-700, Future-Tech Corp., Tokyo, Japan) applying a load of $10 \mathrm{~kg} . K_{I C}$ was calculated from the size of the radial crack pattern according to the formula of Anstis using the elastic modulus obtained from nanoindentation measurements. A total of ten measurements have been conducted for each specimen. Elastic modulus, $E$, have been determined via the nanoindentation technique using a calibrated Berkovich tip G-200 nanoindenter (Agilent Technologies, Santa Clara, USA) up to a depth of $2000 \mathrm{~nm}$ as a means of evaluating the proper consolidation of Y-TZP materials by both microwave and conventional sintering. Indentations have been conducted using the Continuous Stiffness Measurement of a $2 \mathrm{~nm}$ and $45 \mathrm{~Hz}$ harmonic oscillation.

The dynamic coefficient of friction, $C O F$, was calculated from the on-line measured tangential force as the average from all cycles. Fretting loops were obtained for several predefined cycles. After wear testing, the specimens were rinsed in an ultrasonic bath in ethanol for 5 min to remove any loose debris. Due to the size of the tracks, a geometrical approach was used to determine the wear volume by means of white light interferometry (Wyco NT 1100 optical profilometer, Bruker, Bellerica, USA). The measured wear pit dimensions were used to calculate the wear volume. An empirical equation modified from Klaffke ${ }^{30}$ and reported by Kalin et al. ${ }^{31}$ has been employed as a geometrical approximation (Equation 1). The shape of the wear track consists of an elongated round cap due to the fretting conditions applied, which means that the diameter parallel to the sliding motion, $d_{\|}$, is longer than the perpendicular diameter, $d_{\perp}$. 


$$
V=\pi h_{c a p}^{2}\left(R-\frac{h_{c a p}}{3}\right)+\left(\frac{d_{\perp}-d_{\|}}{2}\right)\left[R^{2} \sin \left(\frac{k}{R}\right)-\left(R-h_{c a p}\right) k\right]
$$

The approach to calculate the wear volume must consider two volumes. The first one corresponds to a ball cap of height $h_{\text {cap }}$, which is the wear pit maximum depth. This volume corresponds to the first part of Equation 1. The second one is the portion that results from the oscillating amplitude direction. In this case, the length difference between the diameters can be used to calculate the remaining volume, which is given in the second part of Equation 1. Other parameters considered are the radius of the ball, $R(d=10 \mathrm{~mm})$, and the factor, $k$, which takes into account the irregular geometrical section of the elongated side and is given in Equation 2.

$$
k=\sqrt{2 R h_{c a p}-h_{c a p}^{2}}
$$

Another important tribological parameter that can be obtained from the wear volume is the wear rate, which is given in Equation 3, and has been used to verify whether a gross slip regime has been reached under the selected conditions by comparing it to the fretting regimes proposed by Vingsbo et al. ${ }^{7}$

$$
W_{\text {rate }}=\frac{V}{F_{N} d}
$$

with $V$, the wear volume $\left[\mathrm{mm}^{3}\right], F_{N}$, the normal force $[\mathrm{N}]$ and $d$, the sliding distance $[\mathrm{m}]$.

Track features have been assessed by means of confocal microscopy with a confocal scanning laser microscope (LEXT 3100, Olympus, Tokyo, Japan). Grain size measurements were carried out from FE-SEM images with an image analysis software. The value provided corresponds to the average of 100 grain measurements. In order to determine whether phase transformation has occurred by the fretting action, a Raman spectroscopy analysis has been carried out by obtaining spectrograms on the inside of the wear track and identifying the corresponding tetragonal and monoclinic phase peaks. The Raman spectrometer (LabRam HR UV, HORIBA Jobin Yvon, France) is coupled with a thermoelectrically-cooled multichannel CCD detector. Raman spectra are recorded for a Raman shift range of $120-700 \mathrm{~cm}^{-1}$ as an average of two successive measurements, each with an integration time of $120 \mathrm{~s}$, in order to obtain a well-defined spectrum. 
$2 \mu \mathrm{m}$ is employed.

\section{Results and discussion}

\subsection{Y-TZP ceramics densification and mechanical properties upon sintering}

Table 2 summarizes the properties determined for both materials after microwave (MW) and conventional sintering (CS). The results indicate that all specimens have reached a substantial degree of densification at the selected sintering conditions, as most relative densities are above 99\%. Particularly, LABMW has a significantly higher relative density compared to the CS grades, reaching $99.6 \%$. All specimens result in $H$ and $E$ values above $12 \mathrm{GPa}$ and $200 \mathrm{GPa}$, respectively, which are typical values for $3 \mathrm{Y}$-TZP ceramics. The $K_{I C}$ is not influenced by employing a different sintering method and is comparable to that of the conventionally sintered 3Y-TZP counterparts. However, these values are lower than those expected for Y-TZP materials at approximately 6 $\mathrm{MPa} \cdot \mathrm{m}^{1 / 2}$, as reported in literature ${ }^{32-34}$. Fracture toughness plays an important role in the wear behavior of ceramic materials due to their brittle nature. This property can be used to understand the susceptibility to microcracking and volume wear loss but since the toughness is very similar for all grades, its relevance is limited in this work.

The reported elastic modulus values are very high most probably due to the nanoindentation measurement method and load dependency at loads below $5 \mathrm{~kg}$. Since the fracture toughness is not influenced by the grain size at this range, the contribution of transformation toughening is very modest. Up to $250 \mathrm{~nm}$, transformability of a $3 \mathrm{Y}$-TZP is zero ${ }^{35}$. Only the LVCS has a slightly higher grain size $(343 \mathrm{~nm})$ which might be slightly subjected to transformation under tensile stresses.

Significant differences are given by the average grain size of the specimens, which arise from the sintering method. Two-hundred grains have been measured with an image analysis program using the linear-intercept method. The grain size variations are notably large for the LV grades. In LAB 
materials, there are also significant differences, however they are not as pronounced as in LV. The conditions employed for microwave sintering and the densification mechanisms involved show significantly smaller grain sizes. Several literature reports have indicated a similar behavior, where MW sintering resulted in smaller grain sizes due to the conditions and mechanisms involved ${ }^{8,11,36}$. However, in the case of LAB materials, the grain size difference between MW and CS materials is not statistically different, as they fall within the error range of each other. This might be due to the colloidal pretreatment of the starting powder providing a more homogeneous material in terms of particle size and green packing density ${ }^{26}$. The grain size of LVCS grade is substantially higher than that of LABCS grade due to a pre-sintering step that this material has been subjected to by the manufacturer, which already initiates the formation of necks between particles and, when exposed to conventional sintering conditions, the mechanisms that favor grain growth during sintering are more easily activated.

\subsection{Fretting wear behavior}

Physical and mechanical properties of the Y-TZP balls used as counter-material in the tangential fretting test are summarized in Table 3. This information is useful to understand the wear mechanisms involved in a ball-on-plate configuration. Mechanical properties have been measured in the same way as for sintered materials. As can be seen, the hardness of the ball is within the range of values obtained for the sintered samples. The fracture toughness value is slightly lower in the ball with a significant standard deviation indicating a degree of heterogeneity.

Fretting loops have been analyzed to identify the fretting wear slip regime resulting from the applied conditions under ambient relative humidity. The hysteresis loop in Figure 2 indicates the presence of gross slip after 2,000 and 20,000 cycles for MW sintered LAB material. The loop of the $11^{\text {th }}$ cycle is shown to illustrate the behavior of the tangential force during the initial stages of the fretting test. In this case, the tangential force is limited within -2 and 2 N. During the first few cycles, a partial slip regime is observed, as indicated by a thinner loop. As the number of cycles increases, the loop expands giving rise to gross slip and the tangential force increases substantially 
leading to considerable energy dissipation and wear damage. The displacement of $200 \mu \mathrm{m}$ remains constant throughout all cycles. This tribological behavior is expected for self-mated 3YTZP materials under these wear conditions. Similar results have been obtained for CS ceramics suggesting that MW sintered 3 Y-TZP materials, both LV and LAB, result in a similar wear pattern for the selected processing conditions (dwell temperature, sintering time and heating rates) with respect to the development of tangential forces involved and friction between the ceramic flat and ball counter-material ${ }^{37,38}$.

Results of the mean coefficient of friction, $\mathrm{COF}$, determined for all specimens during fretting are compared in Figure 3. Nath et al. ${ }^{34}$ have reported COF values of approximately 1.0 in self-mated Y-TZP materials in ball-on-plate configurations at similar loads under ambient humidity. The COF values calculated in this work fall within the 0.7-0.85 range. The MW sintered LV ceramic has a statistically lower COF compared to the CS equivalent, as well as all the LAB grades, which have a comparable COF.

In contrast, the LAB materials have a very similar COF of approximately 0.78 , despite different sintering methods and temperatures. This difference can be attributed to the green starting powder compact material. The $\mathrm{LAB}$ material is a more carefully prepared powder with a more homogeneous particle size, which is also reflected in a more uniform sintered grain size. A relationship between COF and grain size shows that as grain size increases so does the COF in the LV material and, since grain size variations amongst the LAB grades are very small, the COF was also constrained to a narrow range. Even though the mechanical properties of LV and LAB are similar, the starting powder characteristics, its further processing and the sintering conditions have an influence on the microstructure of the consolidated body, leading to differences in grain sizes and consequently variations in the COF and fretting sliding interaction between flat and counter material.

In order to measure the wear volume resulting from the fretting tests, the depth of the wear tracks and the length of the radius have been determined by means of light interference profilometry. 
Figure 4 shows profilometry images of the wear tracks after 100,000 cycles on LVMW and LVCS. These ceramics have resulted in the largest difference in COF. An approximate radius $a$ has been calculated as the average of two measurements perpendicular to each other since the tracks are not totally round. In this manner, Equation 1 can be used to determine the wear volume. The measured radii, obtained from profilometry measurements, are shown in Figure 4a and 4b. As can be seen, the deviation from zero eccentricity is quite significant. Nonetheless, for comparative purposes, the proposed method for calculation of the wear volume is still being valid, as all specimens resulted in similar wear track shapes.

The size and shape differences between wear tracks of LVMW and LVCS are significant. The maximum depth of LVMW was measured at $4.5 \mu \mathrm{m}$, while that of LVCS is $5.9 \mu \mathrm{m}$. Additionally, LVMW has considerably shorter radii indicating that a smaller volume of material has been removed due to fretting. A higher degree of roundness can also be observed for the wear track of LVMW. The variation in wear track radius is quite clear in these two examples. For the LAB grades, wear track diameters, depths and shapes are very similar, which is in agreement with the more stable COF values determined previously.

Although the displacement in the fretting tests was fixed to $200 \mu \mathrm{m}$, the contact region and sliding interaction between ball and flat also depends on the microstructure and the properties of the sintered material. For the LV material, these properties are different due to the different sintering conditions, as shown in Table 2. Therefore, the length of the wear track also varies. Radii of more than $400 \mu \mathrm{m}$ have been measured with profilometry and microscopy techniques for LVCS (Figure 4b). In contrast, for the LAB specimens, similarly-shaped wear tracks from the different sintering conditions have been observed. Such behavior might be attributed to the nature of the starting material, which yields a more uniform sintered ceramic in terms of grain size.

For comparative purposes of sintering methods and temperatures, the wear volume has been determined from wear track geometrical features by assuming an elongated round cap shape, as described in Section 2.4. The estimated wear volumes are shown in Figure 5. Error bars 
correspond to the error associated with the measurement of wear tracks. Most values are within the same order of magnitude $\left(10^{5} \mu \mathrm{m}^{3}\right)$. Similar wear volumes have been reported in other studies on self-mated Y-TZP ceramics ${ }^{38}$. However, some notable variations can be seen with respect to processing method and material. When comparing sintering methods for the LV material, the wear volume of LVMW is lower than LVCS grades. A comparison of Figure 3 and 5 indicates that the highest COF results in the highest wear volume (LVCS), but the smallest wear volume does not arise from the lowest COF, which is given by LVMW.

Regarding the LAB ceramics, the calculated wear volumes fall within a very close range from each other and no significant statistical differences can be observed. A more stable wear behavior can be observed in this material. Calculated wear volumes are above $5.5 \times 10^{5} \mu \mathrm{m}^{3}$. In the case of LVCS, the wear volume is higher than for any of the other grades, including those found in LAB. In any case, MW sintering at lower dwell temperatures with shorter processing times and lower energy consumption provides a processing method that allows the consolidation of materials with a tribological behavior comparable to those of CS. An important observation is that the deviation in wear volume increases with bigger tracks due to the approximation approach employed. Nonetheless, the calculated values can be used for the comparison purposes established in this study.

In order to corroborate whether the slip regime under the evaluated fretting conditions corresponds to gross slip, the wear rate of each specimen has been calculated from the wear volume and compared with a fretting regime model taken from Basu et al. ${ }^{40}$, as shown in Figure 6. The results indicate that a gross slip regime has been achieved under the selected fretting conditions in all cases as the wear rates fall within this regime at $200 \mu \mathrm{m}$ amplitude. Due to the similar properties of the sintered bodies, particularly fracture toughness, the wear rates fall within a very close range. This behavior indicates that MW sintering under the selected conditions is able to provide Y-TZP materials for dental applications with the same wear rates as those obtained by CS. In this sense, the durability under fretting wear conditions of the material is not 
compromised by this alternate processing technology. LVCS, which has the highest COF, also has the highest wear rate.

Morphology analysis of the fretting pits and damage has been performed by means of confocal microscopy, as shown in Figure 7. The micrographs illustrate some of the most important microstructural characteristics of fretting wear in Y-TZP ceramics such as delamination, microcracking and abrasive grooving. Also, information regarding the wear mechanisms involved can be obtained. In these materials, fretting wear in ball-on-plate configurations begins with abrasive grooving parallel to the fretting displacement direction due to the sliding contact. This mechanism is characterized by substantially increasing surface roughness. It is then followed by delamination, which corresponds directly to the removal of material. Finally, microcracking at the fretting contacts is responsible for severe wear damage due to cracking-activated spalling and could lead to complete failure of the structural ceramic under higher loads and/or by increasing the number of cycles. Microcracking occurs perpendicular to the fretting displacement direction and might be due to a phenomenon arising from oscillatory motion of contacting surfaces known as fretting fatigue ${ }^{41}$.

Figures $7 \mathrm{a}$ and $7 \mathrm{~b}$ correspond to LVMW and LABMW, respectively, while Figure $7 \mathrm{c}$ and $7 \mathrm{~d}$ belong to LVCS and LABCS, respectively. Figure 7a shows morphological features corresponding to delamination, which is the mechanism responsible for material removal in selfmated zirconia ceramics. The morphology of the fretting pits is quite different among the specimens shown. However, abrasive grooving parallel to the fretting direction can be observed in all cases. LABCS has a maximum pit depth of $1 \mu \mathrm{m}$, is mostly affected by abrasive grooving and no significant microcracking can be appreciated.

LVCS on the other hand, which has the biggest wear volume coupled with the deepest groove of almost $6 \mu \mathrm{m}$, indicates the presence of microcracking and significant delamination. The predominantly whitened center of this fretting pit corresponds to the shallowest depth. The 
fretting pits of the ceramics sintered via MW heating are quite similar with microcracking, delamination and abrasive grooving with maximum pit depths of 4.5 and $4.1 \mu \mathrm{m}$.

Y-TZP ceramics are characterized by a tetragonal-to-monoclinic phase transformation that substantially increases fracture toughness and inhibits crack growth. Therefore, fracture toughness can be an important factor when assessing wear damage in these materials, particularly when it comes to microcracking. The grain size has also been found to influence the wear loss volume, as there is a tendency for reduced wear with decreasing grain size ${ }^{40,42}$. Therefore, both factors need to be taken into consideration. As previously stated, the fracture toughness was not influenced by the sintering method used or the increase in dwell temperature (see Table 2). However, the grain size significantly varied, especially in the LV ceramics.

With respect to the phase transformation induced by fretting, the identification of small monoclinic peaks can be inferred on the Raman spectrograms obtained from the inside of the wear tracks when compared to those of the unworn surface, where it is difficult to discern the peaks from the background since their intensities are very low. The tetragonal to monoclinic transformation can be induced by mechanical stresses in high toughness materials, such as Y-TZP ceramics. The observed microcracks inside the wear tracks can be attributed to the stress induced by the tetragonal to monoclinic transformation. The presence of microcracks and intergranular fractures, as well as the occurrence of grain pull-out, which induces delamination, suggest that tribomechanical wear is the major mechanism responsible for material removal for the selected fretting conditions.

Figure 8 presents the fracture toughness and average grain size against the wear volume after 100,000 fretting cycles. Fretting wear studies on Y-TZP ceramics have established that a lower fracture toughness results in a decreasing wear rate ${ }^{37}$. However, in this case no particular correlation has been found due to very similar $K_{I C}$ values. In the graph, the highest fracture toughness value seems to correspond with the highest wear volume loss. Nonetheless, the fracture toughness values fall within the error range of each other. Hence, it is not possible to conclude 
that the fracture toughness influenced the wear behavior in this case. The differences in wear volume can be, therefore, attributed to other factors such as grain size and yttria content.

Regarding the grain size, a slight tendency of increasing wear volume with increasing grain size has been found for CS specimens, in accordance with the results obtained by Basu et al. ${ }^{37}$. A smaller grain size, obtained in MW sintered specimens, would indicate a higher wear resistance, as determined by Binner et al. ${ }^{38}$ In this case, the wear volume is not statistically different between both materials. The grain size of the LAB materials falls within a narrow range (150 -200 nm) and does not exhibit significant variations in wear volume. However, grain size has a significant effect on the wear volume of the LV material. A grain size of $146 \mathrm{~nm}$ (LVMW) relates to a higher resistance to fretting wear than the specimen sintered by conventional methods, which resulted in a grain size of $343 \mathrm{~nm}$. On the other hand, similar grain sizes obtained for the LAB material, under different sintering conditions, revealed that the wear volume barely varied. Additionally, the smallest grain size did not correspond to a lower wear volume, indicating that a smaller grain size do not improve wear resistance. The lowest wear volume is associated to a grain size of $200 \mathrm{~nm}$. An average wear volume under these fretting conditions results in a value of $6.8 \times 10^{5} \mu \mathrm{m}^{3}$, which falls within a close range of values found in other studies for zirconia ceramics ${ }^{34,43}$. Therefore, the geometrical approximation approach used for the wear volume calculation results in a relatively good estimation for the quantitative characterization of the wear behavior.

\section{Conclusions}

The tribological behavior under fretting wear conditions of two Y-TZP materials sintered at 1200 ${ }^{\circ} \mathrm{C}$ by microwave heating technology has been studied and compared to conventionally sintered specimens at $1400{ }^{\circ} \mathrm{C}$. Upon sintering at the selected conditions, relative densities above $98 \%$ have been obtained. Mechanical properties indicate that microwave-sintered materials comply with the expected values for hardness and fracture toughness, even though a lower sintering temperature, shorter processing times and faster heating rates have been applied, as their values are comparable to those obtained by conventional sintering. Significant variations in grain size 
have been observed on the pre-sintered commercial LAVA. These variations are not as pronounced on the in-house powder that has been carefully prepared prior to sintering.

The influence of processing has been reflected on the microstructure and, hence, on the fretting wear behavior of these materials. The results in LAVA material indicate that large grain sizes, above $300 \mathrm{~nm}$, lead to an increase on the resulting wear volume. Therefore, microwave heating can help reduce grain coarsening when compared to conventional methods due to two main factors: 1) the nature of dielectric heating and 2) the selected processing conditions. As a consequence, a finer microstructure can be obtained and higher wear volume losses can be prevented. In the case of the in-house powder, the effects of sintering on grain growth are not as pronounced, giving place to similar wear volumes. The calculated wear rates indicate that a gross slip regime has been achieved for both sintering conditions. Moreover, the wear mechanisms which include abrasive grooving, delamination and microcracking, are still present in Y-TZP materials even though different sintering methods have been employed. Phase transformation has occurred due to mechanical stresses generated from the fretting action. In general, microwave sintering can still provide materials with a fretting wear resistance comparable to those obtained by conventional sintering using lower dwell temperatures and shorter sintering times for the sintering of individual pieces.

\section{Acknowledgements}

This work has been supported by the Spanish Ministry of Economy and Competitiveness MINECO (project MAT2015-67586-C3-R). A. Presenda acknowledges the Generalitat Valenciana (GV) for his Santiago Grisolía scholarship (GRISOLIA/2013/035). A. Borrell acknowledges the MINECO for her Juan de la Cierva-Incorporación contract (IJCI-2014-19839) and the GV for the financial support under the GV/2014/009 project. M.D. Salvador thanks CAPES - Programa Ciencias sem Fronteiras (Brazil) for the concession of a PVE project No. A086/2013. 


\section{References}

1 M.R. Norton, R. Yarlagadda, and G.H. Anderson, "Catastrophic failure of the Elite Plus total hip replacement, with a Hylamer acetabulum and zirconia ceramic femoral head," $J$. Bone Jt. Surg., 84 [5] 631-635 (2002).

2 M. Guazzato, M. Albakry, S.P. Ringer, and M. V. Swain, "Strength, fracture toughness and microstructure of a selection of all-ceramic materials. Part II. Zirconia-based dental ceramics," Dent. Mater., 20 [5] 449-456 (2004).

I. Denry and J.R. Kelly, "State of the art of zirconia for dental applications," Dent. Mater., 24 [3] 299-307 (2008).

R.B. Waterhouse, Fretting corrosion. Pergamon Press, 1972.

G. Stachowiak and A. Batchelor, Engineering Tribology (Third Edition). ButterworthHeinemann, 2006.

O. Vingsbo and S. Söderberg, “On fretting maps,” Wear, 126 [2] 131-147 (1988).

O. Vingsbo and J. Schön, “Gross slip criteria in fretting,” Wear, 162-164 347-356 (1993).

M. Oghbaei and O. Mirzaee, "Microwave versus conventional sintering: A review of fundamentals, advantages and applications," J. Alloys Compd., 494 [1-2] 175-189 (2010).

M. Gupta and W.L.E. Wong, "Enhancing overall mechanical performance of metallic materials using two-directional microwave assisted rapid sintering," Scr. Mater., 52 [6] 479-483 (2005).

J. Wang, J. Binner, B. Vaidhyanathan, N. Joomun, J. Kilner, G. Dimitrakis, and T.E. Cross, "Evidence for the microwave effect during hybrid sintering," J. Am. Ceram. Soc., 89 [6] 1977-1984 (2006).

S. Charmond, C.P. Carry, and D. Bouvard, "Densification and microstructure evolution of Y-Tetragonal Zirconia Polycrystal powder during direct and hybrid microwave sintering in a single-mode cavity," J. Eur. Ceram. Soc., 30 [6] 1211-1221 (2010).

Z. Xie, J. Yang, and Y. Huang, "Densification and grain growth of alumina by microwave processing," Mater. Lett., 37 [4-5] 215-220 (1998).

R.D. Peelamedu, R. Roy, and D. Agrawal, "Anisothermal reaction synthesis of garnets, ferrites, and spinels in microwave field," Mater. Res. Bull., 36 [15] 2723-2739 (2001).

A. Chatterjee, T. Basak, and K.G. Ayappa, "Analysis of microwave sintering of ceramics," AIChE J., 44 [10] 2302-2311 (1998).

A. Borrell, M.D. Salvador, F.L. Peñaranda-Foix, and J.M. Cátala-Civera, "Microwave sintering of zirconia materials: Mechanical and microstructural properties," Int. J. Appl. Ceram. Technol., 10 [2] 313-320 (2013).

C. García-Gañán, J.J. Meléndez-Martínez, D. Gómez-García, and A. DomínguezRodríguez, "Microwave sintering of nanocrystalline YTZP (3 Mol\%)," J. Mater. Sci., 41 [16] 5231-5234 (2006).

A. Borrell, M.D. Salvador, M. Miranda, F.L. Penaranda-Foix, and J.M. Catala-Civera, "Microwave technique: A powerful tool for sintering ceramic materials," Curr. Nanosci., 10 [1] 32-35 (2014). 

$\mathrm{ZrO}_{2}$ ceramics prepared by microwave sintering, Key Eng. Mater., 633 193-197 (2014).

R. Benavente, M.D. Salvador, F.L. Penaranda-Foix, E. Pallone, and A. Borrell, "Mechanical properties and microstructural evolution of alumina-zirconia nanocomposites by microwave sintering," Ceram. Int., 40 [7 PART B] 11291-11297 (2014).

R. Vasudevan, T. Karthik, S. Ganesan, and R. Jayavel, "Effect of microwave sintering on the structural and densification behavior of sol-gel derived zirconia toughened alumina (ZTA) nanocomposites," Ceram. Int., 39 [3] 3195-3204 (2013).

A. Borrell, M.D. Salvador, E. Rayón, and F.L. Peñaranda-Foix, "Improvement of microstructural properties of 3Y-TZP materials by conventional and non-conventional sintering techniques," Ceram. Int., 38 [1] 39-43 (2012).

C. Monaco, F. Prete, C. Leonelli, L. Esposito, and A. Tucci, "Microstructural study of microwave sintered zirconia for dental applications," Ceram. Int., 41 [1] 1255-1261 (2015).

B. Basu, J.-H. Lee, and D.-Y. Kim, "Development of nanocrystalline wear-resistant YTZP ceramics," J. Am. Ceram. Soc., 87 [9] 1771-1774 (2004).

S.-J. Cho, B.J. Hockey, B.R. Lawn, and S.J. Bennison, "Grain-size and R-curve effects in the abrasive wear of alumina," J. Am. Ceram. Soc., 72 [7] 1249-1252 (1989).

F. Guiberteau, N.P. Padture, and B.R. Lawn, "Effect of grain size on Hertzian contact damage in alumina," J. Am. Ceram. Soc., 77 [7] 1825-1831 (1994).

E. Rayón, R. Moreno, C. Alcázar, M.D. Salvador, F.J. Manjón, E. Jiménez-Piqué, and L. LLanes, "Enhanced hydrothermal resistance of Y-TZP ceramics through colloidal processing," J. Am. Ceram. Soc., 96 [4] 1070-1076 (2013).

K. Matsui, H. Yoshida, Y. Ikuhara, "Phase-transformation and grain-growth kinteics in ytrria-stabilized tetragonal zirconia polycrystal doped with a small amount of alumina," $J$. J. Eur. Ceram. Soc., 30 [7] 1679-1690 (2010).

A. Presenda, M.D. Salvador, F.L. Peñaranda-Foix, R. Moreno, and A. Borrell, "Effect of microwave sintering on microstructure and mechanical properties in Y-TZP materials used for dental applications," Ceram. Int., 41 [5, Part B] 7125-7132 (2015).

J. Zheng, Z.. Zhou, J. Zhang, H. Li, and H.. Yu, "On the friction and wear behaviour of human tooth enamel and dentin," Wear, 255 [7-12] 967-974 (2003).

D. Klaffke, "Fretting wear of ceramics," Tribol. Int., 22 [2] 89-101 (1989).

M. Kalin and J. Vižintin, "Use of equations for wear volume determination in fretting experiments," Wear, 237 [1] 39-48 (2000).

M. Guazzato, M. Albakry, M.V. Swain, and J. Ironside, "Mechanical properties of InCeram Alumina and In-Ceram Zirconia," Int. J. Prosthodont., 15 [4] 339-346 (2002).

G. Magnani and A. Brillante, "Effect of the composition and sintering process on mechanical properties and residual stresses in zirconia-alumina composites," J. Eur. Ceram. Soc., 25 [15] 3383-3392 (2005).

S. Nath, N. Sinha, and B. Basu, "Microstructure, mechanical and tribological properties 
of microwave sintered calcia-doped zirconia for biomedical applications," Ceram. Int., 34 [6] 1509-1520 (2008).

F. Zhang, K. Vanmeensel, M. Inokoshi, M. Batuk, J. Hadermann, B. Van Meerbeek, I. Naert, and J. Vleugels, "3Y-TZP ceramics with improved hydrothermal degradation resistance and fracture toughness," J. Eur. Ceram. Soc., 34 [10] 2453-2463 (2014).

D.D. Upadhyaya, A. Ghosh, G.K. Dey, R. Prasad, and A.K. Suri, "Microwave sintering of zirconia ceramics," J. Mater. Sci., 36 [19] 4707-4710 (2001).

B. Basu, J. Vleugels, and O. Van Der Biest, "Microstructure-toughness-wear relationship of tetragonal zirconia ceramics," J. Eur. Ceram. Soc., 24 [7] 2031-2040 (2004).

J. Binner, B. Vaidhyanathan, A. Paul, K. Annaporani, and B. Raghupathy, "Compositional effects in nanostructured yttria partially stabilized zirconia," Int. J. Appl. Ceram. Technol., 8 [4] 766-782 (2011).

B. Basu, R.G. Vitchev, J. Vleugels, J.P. Celis, and O. Van Der Biest, "Influence of humidity on the fretting wear of self-mated tetragonal zirconia ceramics," Acta Mater., 48 [10] 2461-2471 (2000).

B. Basu and M. Kalin, Tribology of Ceramics and Composites: A Materials Science Perspective. John Wiley and Sons, 2011.

A.E. Giannakopoulos and S. Suresh, "A three-dimensional analysis of fretting fatigue," Acta Mater., 46 [1] 177-192 (1998).

A. Krell and D. Klaffke, "Effects of grain size and humidity on fretting wear in finegrained alumina, $\mathrm{Al}_{2} \mathrm{O}_{3} / \mathrm{TiC}$, and zirconia," J. Am. Ceram. Soc., 79 [5] 1139-1146 (1996).

B. Basu, R.G. Vitchev, J. Vleugels, J.P. Celis, and O. Van Der Biest, "Fretting wear of self-mated tetragonal zirconia ceramics in different humidity," Key Eng. Mater., 206-213 [I] 783-786 (2001). 


\section{Figure captions:}

Figure 1. Fretting wear setup and conditions.

Figure 2. Fretting hysteresis loops of the $11^{\text {th }}, 2,000^{\text {th }}$ and $20,000^{\text {th }}$ cycle for microwave sintered LAB material revealing that a partial slip or gross slip regime occurs under the selected fretting conditions.

Figure 3. $\mathrm{COF}$ of the $3 \mathrm{Y}$-TZP ceramics during tangential fretting tests.

Figure 4. Confocal light microscopy profiles of (a) LVMW and (b) LVCS materials.

Figure 5. Wear volume for LV and LAB ceramics after microwave and conventional sintering.

Figure 6. Wear rates of all ceramics grades at $200 \mu \mathrm{m}$ fretting amplitude plotted on top of the fretting regime model ${ }^{39}$.

Figure 7. Confocal microscopy images of wear pits after 100,000 cycles for a) LVMW, b) LABMW c) LVCS and d) LABCS showing delamination and microcracking.

Figure 8. Plot of the average grain size and fracture toughness against wear volume for the studied YTZP materials. 